\title{
Synthesis and Characterization of Ni-Co Electrocatalyst for Hydrogen Evolution Reaction in Acidic Media
}

\author{
Yufang Yang*, Huan Yang, Changjin Liang, Xun Zhu \\ School of Material Science and Engineering, Hanshan Normal University, Chaozhou 521041, China \\ *E-mail: zzyufang@163.com
}

doi: $10.20964 / 2018.07 .72$

Received: 23 February 2018 / Accepted: 7 May 2018 / Published: 5 June 2018

\begin{abstract}
$\mathrm{Ni}$-Co was electrodeposited onto titanium substrates, as a non-noble metal electrocatalyst. The surface morphology and microstructure were observed by scanning electron microscopy (SEM) and X-ray diffraction (XRD). The electrocatalytic properties of Ni-Co for hydrogen evolution reaction (HER) in acid solution were investigated by using cathodic polarization, Tafel curves, electrochemical impedance spectroscopy (EIS), cyclic voltammetry and chronoamperometry. The surface is rough with uniform, compact and fine spherical particles on it. The Ni-Co is a face centered cubic (fcc) solid solution. The results show that HER on Ni-Co electrodes takes place by the Volmer- Heyrovsky mixing mechanism. With an increase of Co content in the electrode, and with the increase of sulfuric acid concentration and temperature, the cathodic polarization and the electrochemical reaction resistance of HER decrease, the exchange current density increases, and the electrocatalytic activity of $\mathrm{Ni}-\mathrm{Co}$ for HER is enhanced. The $\mathrm{Ni}_{64.4} \mathrm{Co}_{35.6}$ shows the highest electrocatalytic activity for HER, with better stability and corrosion resistance. It can be used as an active, stable and inexpensive electrocatalyst for the HER in acidic media.
\end{abstract}

Keywords: Ni-Co alloys; Electrodeposition; Electrocatalysis; Hydrogen evolution reaction; Acidic media

\section{FULL TEXT}

(C) 2018 The Authors. Published by ESG (www.electrochemsci.org). This article is an open access article distributed under the terms and conditions of the Creative Commons Attribution license (http://creativecommons.org/licenses/by/4.0/). 